\title{
Anther and pollen development in sweet cherry (Prunus avium L.) in relation to winter dormancy
}

Erica Fadón $^{1,2} \cdot$ María Herrero $^{2} \cdot$ Javier Rodrigo $^{1}$

${ }^{1}$ Centro de Investigación y Tecnología Agroalimentaria de Aragón. Instituto Agroalimentario de Aragón IA2 (CITA-Universidad de Zaragoza), Av. Montañana 930, 50059 Zaragoza, Spain.

${ }^{2}$ Estación Experimental Aula Dei, CSIC, Av. Montañana 1005, 50059 Zaragoza, Spain

jrodrigo@aragon.es, +34 976716314

${ }^{1} 0000-0002-3499-1602 ;{ }^{2} 0000-0002-8321-1764$

\begin{abstract}
Anther and pollen development is a highly conserved process in angiosperms, but while pollen formation in annual plants occurs in a few days, in temperate woody perennials it requires several months. How anther and pollen development is framed in terms of seasonality plays a clear part in reproductive success. In this study, seasonal anther and pollen development is characterized in 2 sweet cherry cultivars over 2 years, paying special attention to the period of dormancy and unveiling the role of starch in this process. We evaluated starch content from the autumn until bud burst with the help of an image analysis system fitted to a light microscope. Microscope observations allowed the temporal relationship of pollen development to the phenological stages of flower and bud development to be determined. In both cultivars and years, anther and pollen development followed the same pattern. Development was halted by dormancy, when the anthers showed no morphological changes until several weeks after chilling fulfilment, until the milder temperatures reactivated development. After dormancy, starch was accumulated in the connective tissue until tracheary element differentiation. Quantification of starch in the connective tissue of anthers revealed its importance in supporting pollen meiosis and subsequent anther growth.
\end{abstract}

Keywords Anther meiosis · Chilling fulfilment · Flower development · Growing Degree Hours · Starch · Temperate fruit trees

Acknowledgements This work was supported by the Ministerio de Ciencia, Innovación y Universidades — European Regional Development Fund, European Union: Instituto Nacional de Investigación y Tecnología Agraria y Alimentaria [grant numbers RFP2015-00015-00, RTA2014-00085-00, RTA201700003-00]; and Gobierno de Aragón — European Social Fund, European Union [Grupos Consolidados A43, A12_17R]. 


\section{Introduction}

Anther and pollen development is a highly conserved process in angiosperms, whose phases have been well characterized in model plants such as Arabidopsis thaliana (Owen and Makaroff 1995; Vogler et al. 2017), tobacco (Nicotiana tabacum; Koltunow et al. 1990) and tomato (Lycopersicon esculentum; Brukhin et al. 2003). The anther is the part of the stamen where male gametophytes develop. Anther consists of two thecae, each forming of two adjacent microsporangia that are linked by the connective tissue, which transports the nutrients from the plant towards the anther (Pacini and Dolferus 2016). During anther differentiation, the sporogenous cells give rise to the microspores and are located centrally within each microsporangia, and the non-reproductive cells form discrete layers surrounding the sporogenous tissue. From outside to inside, the epidermis functions as protection, the endothecium and middle layers are involved in carbohydrates management, and the glandular tapetum implements a nutritive function and controls secretion of different substances (Pacini 2010). Pollen development occurs in two successive developmental phases, microsporogenesis and microgametogenesis. During microsporogenesis, the meiotic division of the sporophytic meiocytes of the four microsporangia results in the formation of tetrads of haploid microspores enclosed by a callose wall (Ma 2005). The microspores become independent once the enzymes secreted by the tapetum dissolve the callose that held them together (Pacini and Dolferus 2016). During the second phase, microgametogenesis, the microspores enlarge and become vacuolated (Pacini et al. 2011) and differentiate as pollen grains following one or two haploid mitotic divisions (Carrizo García et al. 2017).

While these phases take place in all angiosperms, each species presents its own peculiarities (Lora et al. 2009a; Gotelli et al. 2016; Kim et al. 2016; Zini et al. 2017), and both anther and pollen development occurs under very different conditions and timing (Carrizo García et al. 2017). Pollen formation in annual plants lasts just a few days (Koltunow et al. 1990; Smyth et al. 1990). In contrast, woody perennials in temperate and cold regions require several months for the same process, since they enter into a dormant stage to survive the low winter temperatures (El-Ghazaly and Grafström 1995; Julian et al. 2011; Mirgorodskaya et al. 2015).

Temperate woody species require cold winter temperatures for release from dormancy and proper flowering (Rohde and Bhalerao 2007; Kurokura et al. 2013). In temperate fruit trees, different states of winter dormancy are considered: endodormancy, regulated by physiological factors that require the exposure to a specific range of chilling temperatures; and ecodormancy, regulated by environmental factors 
(Lang et al. 1987). Chilling requirements vary depending on the genotype, being the main determinant of cultivar adaptation to different areas (Luza and Polito 1988; Jansson and Douglas 2007; Herrero et al. 2017). However, despite the importance of dormancy in woody perennials, the biological processes occurring inside each bud are not completely understood (Fadón and Rodrigo 2018). The process of meiosis in anthers, resulting in the formation of young microspores, is a phase that is very sensitive to freezing (Mamun et al. 2006; Ohnishi et al. 2010; Barton et al. 2014), and has to be well synchronized with seasons to avoid damage.

In Prunus species, since blooming occurs at early spring before leaf emergence as in other histerant species, the reproductive process relies on stored reserves within the flower (Rodrigo et al. 2000, 2009) or from other parts of the tree (Loescher et al. 1990). Starch has been traditionally associated with stored reserves (Zeeman et al. 2010), and recently it has also been linked with mitigation of abiotic stress (Thalmann and Santelia 2017), and the regulation of flower and early embryo development (Hedhly et al. 2016). Starch dynamics in the ovary during the spring has been associated with key reproductive events in different fruit tree species, including ovule and embryo sac development (Rodrigo and Herrero 1998; Rodrigo et al. 2000; Rodrigo et al. 2009), pollen-pistil interactions, and fertilization and fruit set (Ruiz et al. 2001; Iglesias et al., 2003; Lebon et al. 2004; Alcaraz et al. 2013). Indirect evidence in different species supports starch reserves in the stamen being related to the support of pollen development (Clement and Pacini 2001; Pacini 2009; Lora et al. 2009b; Konyar 2013). However, no direct evidence has been reported yet, which may be due to the small size of the anther structures and the high compartmentalization of starch in the different tissues, therein that makes analytical analysis difficult (Chow and Landhausser, 2004). To address this issue, in this study starch content in the anther was quantified with the help of an image analysis system fitted to a light microscope. This approach has previously proven successful for the quantification of starch in different parts of the pistil (Rodrigo and Herrero 1998; Rodrigo et al. 2000; Alcaraz et al. 2013; Fadón et al. 2018).

In this study, anther and pollen development have been comprehensively characterized in 2 sweet cherry (Prunus avium) cultivars over a period of 2 years. To examine the implications of starch dynamics in the anther on pollen development, seasonal anther and pollen development have been characterized in relation to winter dormancy up to anthesis. Starch content in the anthers was quantified to study its fluctuations in relation to anther and pollen development . 


\section{Materials and methods}

\section{Plant material}

Three trees of the sweet cherry cultivars Bing and Burlat were selected from an experimental orchard at Centro de Investigación y Tecnología Agroalimentaria (CITA), Zaragoza, Spain; at 4144’30”N, 047’00” $\mathrm{W}$ and $220 \mathrm{~m}$ above sea level.

\section{Determination of breaking of dormancy and estimation of chilling requirements}

For the estimation of breaking of dormancy, 3 shoots per cultivar $(15-30 \mathrm{~cm}$ length and $5 \mathrm{~mm}$ diameter, with at least 10 flower buds) were randomly collected weekly during the winter. Dormancy status of shoots was determined by an evaluation of the response of the flower buds after a week in the growth chamber (Fadón and Rodrigo, 2018). To have a reference point with which to follow bud growth, 10 flower buds were also randomly picked in the field and individually weighted. Shoots were placed on water soaked florist foam and maintained in a growth chamber at $22 \pm 1{ }^{\circ} \mathrm{C}$ with a 12 hours light photoperiod. The end of dormancy was established when the flower buds had increased in weight by at least $30 \%$ after 7 days in the chamber.

Hourly temperatures were recorded during 2010 - 2011 and 2011 - 2012 at a meteorological station located in the experimental orchard. Winter temperatures varied over the 2 years, with a very mild autumn during the second year that resulted in significantly higher minimum temperatures in November and December than in the first year (Fig. 1). Winter chilling accumulation was calculated according to the "Utah Model" (Richardson et al. 1974), from October 1st until the end of dormancy. Heat requirements were calculated using the Growing Degree Hours (GDH) model (Richardson et al. 1975) from the end of dormancy until anthesis. The different winter temperatures between years resulted in a lower chilling accumulation during the second year (Fig. 1).

\section{Flower development characterization and microscope preparations}

External flower bud phenology was characterized according to the BBCH code for sweet cherry (Table 1) (Fadón et al. 2015). The development of the internal flower primordia was examined in 3 flower buds collected every week from the end of summer to bud burst and every 2 days from bud burst until anthesis. At least one out of the 1 - 4 flower primordia per bud was dissected, examined and photographed under a 
Leica MZ-16 stereoscopic microscope with a Leica DC-300 digital camera (Leica Microsystems, Cambridge, UK).

For pollen development characterization, another set of 2 flower buds per cultivar was collected, fixed in glutaraldehyde, embedded in resin and $2 \mu \mathrm{m}$ thick sections were cut. Sections were stained for general histology with periodic acid-Schiff reagent (PAS) and toluidine blue, to identify nuclei with 4',6diamidino-2-phenylindole (DAPI), for callose with aniline blue, for cellulose with calcofluor and for tracheary elements with auramine, according to standard methods (Julian et al. 2011; Fadón et al. 2018). They were then examined under a Leica DM2500 microscope, equipped with a Leica DFC-310 digital camera and the software Leica Application Suite, Version 4.2.0 (Leica Microsystems, Cambridge, UK).

\section{Starch quantification and determination of anther size by image analysis}

For starch observation and quantification, another set of 3 flower buds was randomly collected every 2 weeks from the end of the summer to bud burst during 2 consecutive years. The buds were fixed, embedded in paraffin wax, sectioned at $10 \mu \mathrm{m}$ and stained with potassium iodide-iodine $\left(\mathrm{I}_{2} \mathrm{KI}\right)$ following the protocol described by Fadón et al. (2018).

Starch content was quantified in 4 - 6 flower primordia per sampled day by image analysis using the method described by Rodrigo et al. (1997), with modifications (Fadón et al. 2018). In 4 middle anther sections per flower primordium, starch was quantified in a frame of connective tissue under the vascular bundle (Fig. 2a). Starch granules were clearly distinguishable (Fig. 2b) and recognizable by the image analyser. Thus, a binary image of starch was used as a superimposed mask on the black and white original image (Fig. 2c). The starch content was considered the sum of the optical densities under the mask.

To correlate possible variations in nutritional status of the anthers with morphological changes, the relationship between starch content and anther size was studied. For this purpose, anther size, considered as the mean of the 2 perpendicular diameters, was measured in the same preparations previously used to measure starch content, using the same image analysis system.

\section{Statistical analyses}

Analysis of starch content and anther size was performed using SPSS for Windows, Version 12.0 statistical software (SPSS Inc., Chicago, IL, USA). When one-way analysis of variance (ANOVA) generated a significant F-value, mean separations were determined by Duncan's multiple-range test. Correlations 
between anther size and heat accumulation from chilling fulfilment were calculated for the 2 cultivars over the 2 years. Correlations were analysed by Pearson correlation coefficients at the 0.01 level. 


\section{Results}

\section{Anther development and dormancy}

At the end of the summer, prior to dormancy establishment, flower primordia started developing and showed incipient verticiles: sepals, petals, anthers and pistil (Fig. 3a). A close examination of anther locules showed that sporogenous tissue and the parietal cell layers started to be distinguishable. Sporogenous tissue and the surrounding layers had already proliferated (Fig. 3b). Development continued until late October, when the flower buds stopped growing. At winter dormancy, the sporogenous tissue had already differentiated into the pollen mother cells with a characteristic polyhedral shape and a thin callose wall. Tapetum, middle layers, endothecium and epidermis were also differentiated (Fig. 3c). After breaking dormancy, the first change observed in pollen mother cells was the formation of vacuoles, switching from a dense to a highly vacuolated cytoplasm (Fig. 3d).

The determination of breaking of dormancy in both cultivars showed that Burlat had lower chilling requirements $(981 \pm 83 \mathrm{CU})$ than Bing $(1082 \pm 27 \mathrm{CU})$. The first year studied, chilling fulfilment occurred the first week of January for cultivar Burlat, and a week later, for cultivar Bing. Winter temperatures were milder during the second year, which resulted in a 16 - 18 day difference between both years for the chilling fulfilment of each cultivar.

In spite of differences in the dates of chilling fulfilment between cultivars and years, a similar pattern of anther development was observed in relation to dormancy for the 2 cultivars during this 2 year study (Fig. 4). Anthers remained at the sporogenous tissue stage approximately 5 months during winter. This period corresponded to endodormancy and the following 6 - 7 weeks represented ecodormancy (Fig. 4). Then pollen mother cells underwent meiosis, which lasted approximately a week. From meiosis, pollen development was completed in approximately 3 - 4 weeks (Fig. 4).

\section{Microsporogenesis and microgametogenesis}

Anthers presented a very slight sign of development at the beginning of microsporogenesis; there were no external developmental cues, with flower buds remaining at stage 50 of the BBCH code (Fig. 5a). Microsporogenesis began with a clear isolation of pollen mother cells (Prophase I) that did not show vacuoles and were surrounded by thick callosic walls (Fig. 5b). By this time, pollen mother cells showed an accumulation of starch, which subsequently vanished before meiosis. Despite the thick callose layer, 
pollen mother cells were connected through cytomictic channels. Synchronized with this, conspicuous changes occurred in the tapetum, which by this time was composed of cells with a dense cytoplasm. Both the first and second meiotic divisions occurred when the pollen mother cells were completely isolated from each other. Once Telophase II was reached, the 4 nuclei formed after meiosis were surrounded by callose. The first sign of cytokinesis was cell plate formation, followed by callose deposition (Fig. 5c) and the distribution of the cytoplasm to the 4 microspores. Concomitantly, the tapetum started to degenerate. Cytokinesis was completed when the inner callose walls joined at the centre completely isolating the 4 microspores, which remained together as a tetrad (Fig. 5d). Vacuole formation in the cytoplasm of each microsporocyte, started to be observed. By the end of microsporogenesis, flower buds had started to swell, and had reached phenological stage 51 of the $\mathrm{BBCH}$ code.

At bud burst, BBCH stage 53, the colour of anthers changed from green to bright yellow (Fig. 6a). Callose degeneration and the subsequent release of microspores marked the beginning of microgametogenesis. Free microspores presented inward apertures and a cytoplasm with big vacuoles (Fig. 6b). Tapetal cells lost their cell walls and started to degenerate (Fig. 6c). At BBCH stage 57, flower petals had emerged from each bud, and the stamen filaments had significantly elongated (Fig. 6d). Microspores had already undergone the first mitotic division presenting 2 nuclei, vegetative and generative, the latter stainined intensely with DAPI (Fig. 6e). Young pollen grains with a fully developed exine and intine presented as spherical shapes with dense cytoplasm and significant starch accumulation. By this time, the tapetum had completely disappeared and the endothecium had fibrous thickening (Fig. 6f). At BBCH stage 59, flowers were at the balloon stage (Fig. 6g). Mature pollen grains acquired triangular shapes in polar view, with the vegetative nuclei and the generative cells lying together in the middle (Fig. 6h) surrounded by a dense cytoplasm, while starch was progressively consumed. At this point, with the degeneration of the middle layer, only 2 of the original 4 cell layers that made up the locule wall persisted (Fig. 6i).

\section{Starch and vascular tissue}

The connective cells of the anthers showed changes in their starch content along the seasons. The indirect quantification of which showed a characteristic pattern for the two cultivars and allowed comparing the amount of starch detected under the different conditions of the two years studied (Fig. 7). Anther cells were devoid of starch during the autumn and winter, but some traces were observed at the end of winter. Then, a significant peak of accumulation and subsequent hydrolysis occurred following dormancy, about 6 - 7 
weeks after chilling fulfilment, concomitantly with the presence of the tetrads in the microsporangia (Fig. 7). In both cultivars, the peak of starch content occurred earlier and reached a higher value in the first year (Fig. 7a, c), with a colder winter and earlier date of chilling fulfilment, and a warmer spring (higher GDH accumulation), than during the second year (Fig. 7b, d).

The average anther diameter was about $0.2 \mathrm{~mm}$ during the autumn, which increased to about 0.4 $\mathrm{mm}$ at dormancy establishment, in all cases studied. This size was maintained without significant variation during the colder winter (Fig. 7a, c); an increase in growth was detected at the end of winter during the milder year, especially for cultivar Bing (Fig. 7b). In all cases, anther growth resumed exponentially in the early spring, just after the starch accumulation peak. The increase in anther size after chilling fulfilment was concomitant with GDH accumulation; both parameters were significantly correlated in all cases $(\mathrm{p}<$ 0.01; Fig. 7).

The procambium presented as non-differentiated provascular tissue, and no morphological changes were detected during winter dormancy (Fig. 8a). After dormancy, concomitant with the accumulation of starch in the connective tissue (Fig. 8b), first tracheary elements appeared, indicating procambium activation (Fig. 8c). Following starch consumption (Fig. 8d) the number of tracheary elements progressively increased (Fig. 8e). 


\section{Discussion}

\section{Anther development during dormancy}

The anthers in sweet cherry started to differentiate at the end of the summer, and progressively acquired their characteristic shape over the winter. During dormancy all flower buds were at phenological stage 50 in the BBCH scale (Fadón et al. 2015b), with the flower buds closed and covered by dark brown scales. No external phenological changes were observed until bud burst in early spring. Flower primordia remained at the same stage of development during dormancy, characterized by the presence of all flower whorls, with the pistil showing an incipient ovary, style and stigma, and the anthers clearly differentiated in 4 groups of archesporial cells (Fadón et al. 2018). At winter dormancy, anther wall development was already completed with the formation of the epidermis, the endothecium, the middle layer and the tapetum; and the sporogenous tissues had already differentiated into pollen mother cells. This stage of anther development during dormancy has been reported in other Prunus species (Felker et al. 1983; Julian et al. 2011), supporting the idea that anther development is a conserved process (Koltunow et al. 1990; Owen and Makaroff 1995; Brukhin et al. 2003; Vogler et al. 2017). However, further studies are required to establish whether this stage during dormancy is conserved in other woody perennials, since in other species, such as Rhododendron (Mirgorodskaya et al. 2015) and hazel (Corylus avellana; Frenguelli et al. 1997), meiosis occurs before dormancy and bicellular pollen grains have been observed during the winter.

In sweet cherry, the anthers remained in this stage for 5 months, a significantly longer period than previously reported for apricot (Prunus armeniaca; Julian et al. 2011). The flower primordia remain unchanged in this stage of anther development during both endo- and eco-dormancy.

\section{The timing of meiosis and further pollen development}

First detectable changes in the anthers occurred after ecodormancy just prior to bud burst; firstly, there was a rapid increase of starch accumulation and then the triggering of pollen meiosis. Between 6 and 7 weeks elapsed from chilling fulfilment to meiosis, in agreement with previous reports in other fruit tree species, such as sour cherry and Japanese pear (Pyrus pyrifolia; Saito et al. 2015), apple (Malus domestica; Bubán and Faust 1995) and peach (Prunus persica; Citadin et al. 2002). However in apricot, pollen meiosis has been reported as a potential marker of chilling fulfilment since both events occurred sequentially or nearly simultaneously (Julian et al. 2011). 
Results described in this paper allowed a framing of pollen development in the phenological stages of the BBCH code for cherry (Fadón et al. 2015). While flower buds were dormant at BBCH stage 50, sporogenous tissue had already differentiated in the anthers. Meiosis and tetrad formation occurred during BBCH stage 51 (early bud burst). Subsequent rapid flower growth corresponded with further pollen development, microspores formation occurred at $\mathrm{BBCH}$ Stage 53, during which time the anthers acquired a bright yellowish colour, as has been reported in apricot (Julian et al. 2014). Pollen mitosis and pollen grain starch accumulation took place at $\mathrm{BBCH}$ Stages 56 - 57 (flower elongation and petal tips visible). Finally, the degeneration of the middle layer, the fibrous thickening of the endothecium, and pollen maturation just before anther dehiscence corresponded to bloom (BBCH stage 59). The synchronization between flower and pollen development in sweet cherry was in agreement with previous reports for annual species, although their time required for the same process is significantly shorter (Brukhin et al. 2003; Kim et al. 2016).

Pollen development from meiosis to mature pollen occurred within 3 - 4 weeks in both cultivars, approximately one week less than that reported for the cultivars 'Stella' and 'Durone I di Vignola' in a colder area (Pacini et al. 1986). Although pollen formation is a conserved process in angiosperms, the time required to complete the process is highly variable among species. Annual plants such as tobacco (Koltunow et al. 1990) and Arabidopsis (Smyth et al. 1990) require just 4 - 5 days to complete this process. Different developmental rates among species also occur in other conserved reproductive processes, such as the phase from pollination to fertilization, which is also slower in woody plants than in annuals (Williams 2012a; 2012b).

\section{Starch as a key to success}

The cells of the anther, both reproductive and non-reproductive, were devoid of starch during the autumn and winter. In early spring, the pattern of starch accumulation and subsequent hydrolysis in different anther tissues was closely related to key events in both anther and pollen development. This supports the idea that starch metabolism is developmentally regulated during sexual reproduction (Hedhly et al. 2016).

Starch appearance in the anthers initially occurred in the provascular tissue, and thus, preceded tracheary element differentiation, which transport the nutrients from the plant towards the anther (Pacini and Dolferus 2016). The connective tissue progressively accumulated a high amount of starch to reach a maximum value when pollen meiosis took place. Subsequently, starch vanished concomitant with the 
exponential growth of the anthers and pollen maturation in the following days. Starch storage preceded anther and pollen development that demands large amounts of energy, supporting the function of starch in the anther as nourishment of the developing pollen grains (Pacini 2010). However, to what extent those starch reserves are mobilized from sugars accumulated during chilling accumulation or from other parts of the plant is not clear.

Differences in starch content between years for both cultivars were related to differences in winter temperatures, showing the influence of temperatures in anther and pollen development. The peak of starch accumulation occurred at early bud burst, likely in response to warm temperatures after chilling fulfilment. The warm temperatures through the spring season appeared to influence when the starch accumulation occurred, $10-12$ days earlier in the year with the colder winter and warmer spring. The amount of starch appeared to be influenced by the accumulation of chilling during winter, since higher values were found during the colder winter for both cultivars. Temperature has been previously reported to affect pollen viability in sweet cherry, both low and high temperatures affect the pollen performance (Hedhly et al. 2004).

During pollen development, pollen mother cells accumulated starch just before the first meiotic division. Then, while microspores appeared filled with starch at the uninucleate stage, bicellular pollen grains were devoid of starch. These cycles of starch seem to be a conserved feature of anther and pollen development, since they have been described in different species (Lora et al. 2009b; Reale et al. 2009; Julian et al. 2011; Konyar 2013; Hedhly et al. 2016). This sequence of cycles of starch accumulation and hydrolysis supports the idea that starch accumulated in the anther support the last phases of pollen development (Pacini et al. 2011).

Cycles of accumulation and hydrolysis of starch in the connective tissue of the anthers have been quantified for the first time in this work, in a similar way as our previous quantification of starch content in the pistil (Fadón et al. 2018) . Ovary primordia accumulate starch during dormancy, reaching a maximum at chilling fulfilment with subsequently consumption during ecodormancy (Fadón et al. 2018). However, starch accumulation in the developing anther took place during ecodormancy preceding bud burst, showing an association with the early growth of the anther prior to meiosis, an event that coincided with the maximum peak of starch accumulation. This suggests that starch reserves in the anther might be intended to support the process of pollen meiosis and early anther growth at budburst, in a similar manner as starch 
in the ovary has been associated with supporting pistil development and key reproductive events during the onset of fruit development (Rodrigo et al. 2000; Lebon et al. 2004; Alcaraz et al. 2013; Fadón et al. 2018).

In sweet cherry, anther and pollen development followed a conserved pattern through the seasons, from the summer to bloom in the following spring. This process was halted by dormancy, when pollen mother cells with a thin callosic wall differentiated, remaining without morphological changes during chilling accumulation. Several weeks after the chilling fulfilment, initial changes were associated with starch accumulation in the connective tissue, at the provascular stage before differentiation of tracheary elements. Quantification of starch in the connective tissue of the anthers allowed relating the starch dynamics with the accumulation of chilling and heat temperatures, and stablishing the pattern of the reserves along the seasons. This revealed the implications of starch in the support of pollen meiosis and subsequent anther growth, showing that both processes are conditioned by temperature after breaking dormancy in the weeks before flowering. 


\section{REFERENCES}

Alcaraz ML, Hormaza JI, Rodrigo J (2013) Pistil starch reserves at anthesis correlate with final flower fate in avocado (Persea americana). PLOSOne 8:e78467. doi: 10.1371/journal.pone.0078467

Barton DA, Cantrill LC, Law AMK, et al (2014) Chilling to zero degrees disrupts pollen formation but not meiotic microtubule arrays in Triticum aestivum L. Plant Cell Environ 37:2781-2794. doi: $10.1111 /$ pce. 12358

Brukhin V, Hernould M, Gonzalez N, Chevalier C (2003) Flower development schedule in tomato Lycopersicon esculentum cv. sweet cherry. Sex Plant Reprod 15:311-320. doi: 10.1007/s00497-0030167-7

Bubán T, Faust M (1995) New aspects of bud dormancy in apple trees. Acta Hortic. 395:105-111.

Carrizo García C, Nepi M, Pacini E (2017) It is a matter of timing: asynchrony during pollen development and its consequences on pollen performance in angiosperms-a review. Protoplasma 254:57-73. doi: 10.1007/s00709-016-0950-6

Chow PS, Landhausser SM (2004) A method for routine measurements of total sugar and starch content in woody plant tissues. Tree Physiol 24:1129-1136. doi: 10.1093/treephys/24.10.1129

Citadin I, Bassols MC, Gilberto F, et al (2002) Meiosis stage as an indicator for peach endodormancy. Rev Bras Frutic 24:23-28.

Clement C, Pacini E (2001) Anther plastids in angiosperms. Bot Rev 67:54-73.

El-Ghazaly G, Grafström E (1995) Morphological and histochemical differentiation of the pollen wall of Betula pendula Roth. during dormancy up to anthesis. Protoplasma 187:88-102.

Fadón E, Herrero M, Rodrigo J (2015) Flower development in sweet cherry framed in the BBCH scale. Sci Hortic (Amsterdam) 192:141-147. doi: 10.1016/j.scienta.2015.05.027

Fadón E, Herrero M, Rodrigo J (2018) Dormant flower buds actively accumulate starch over winter in sweet cherry. Front Plant Sci doi: 10.3389/fpls.2018.00171

Fadón E, Rodrigo J (2018) Unveiling winter dormancy through empirical experiments. Environ Exp Bot 152: 28-36. doi: 10.1016/j.envexpbot.2017.11.006

Felker FC, Robitaille HA, Hess FD (1983) Morphological and ultrastructural development and starch accumulation during chilling of sour cherry flower buds. Am J Bot 70:376-386.

Frenguelli G, Ferranti F, Tedeschini E, Andreutti R (1997) Volume changes in the pollen grain of Corylus avellana L. (Corylaceae) during development. Grana 36:289-292. doi: 10.1080/00173139709362619

Gotelli MM, Galati BG, Zarlavsky G, Medan D (2016) Pollen and microsporangium development in Hovenia dulcis (Rhamnaceae): a different type of tapetal cell ultrastructure. Protoplasma 253:11251133. doi: 10.1007/s00709-015-0870-x

Hedhly A, Hormaza JI, Herrero M (2004) Effect of temperature on pollen tube kinetics and dynamics in sweet cherry, Prunus avium (Rosaceae). Am J Bot 91:558-564. doi: 10.3732/ajb.91.4.558

Hedhly A, Vogler H, Schmid MW, et al (2016) Starch turnover and metabolism during flower and early embryo development. Plant Physiol pp.00916.2016. doi: 10.1104/pp.16.00916

Herrero M, Rodrigo J, Wunsch A (2017) Flowering, fruit set and development. In: Quero-Garcia J, Iezzoni A, Lang G, Pulawska J (eds) Cherries: Botany, Production and Uses. CAB International, Boston, pp $14-35$

Iglesias DJ, Tadeo FR, Primo-Millo E, Talon M (2003) Fruit set dependence on carbohydrate availability in citrus trees. Tree Physiol 23:199-204. doi: 10.1093/treephys/23.3.199

Jansson S, Douglas CJ (2007) Populus: a model system for plant biology. Annu Rev Plant Biol 58:435-58. 
doi: 10.1146/annurev.arplant.58.032806.103956

Julian C, Herrero M, Rodrigo J (2014) Anther meiosis time is related to winter cold temperatures in apricot (Prunus armeniaca L.). Environ Exp Bot 100:20-25. doi: 10.1016/j.envexpbot.2013.12.002

Julian C, Rodrigo J, Herrero M (2011) Stamen development and winter dormancy in apricot (Prunus armeniaca). Ann Bot 108:617-25. doi: 10.1093/aob/mcr056

Kim Y-J, Jang M-G, Zhu L, et al (2016) Cytological characterization of anther development in Panax ginseng Meyer. Protoplasma 253:111-1124. doi: 10.1007/s00709-015-0869-3

Koltunow AM, Truettner J, Cox KH, et al (1990) Different temporal and spatial gene expression patterns occur during anther development. Plant Cell 2:1201-1224. doi: 10.1105/tpc.2.12.1201

Konyar S (2013) Ultrastructure of microsporogenesis and microgametogenesis in Campsis radicans (L.) Seem. (Bignoniaceae). Plant Syst Evol 300:303-320. doi: 10.1007/s00606-013-0883-x

Kurokura T, Mimida N, Battey NH, Hytönen T (2013) The regulation of seasonal flowering in the Rosaceae. J Exp Bot 64:4131-41. doi: 10.1093/jxb/ert233

Lang GA, Early JD, Martin GC, Darnell RL (1987) Endodormancy, paradormancy, and ecodormancy Physiological terminology and classification for dormancy research. HortScience 22:371-377.

Lebon G, Duchene E, Brun O, et al (2004) Flower abscission and inflorescence carbohydrates in sensitive and non-sensitive cultivars of grapevine. Sex Plant Reprod 17:71-79. doi: 10.1007/s00497-0040217-9

Loescher WH, McCamant T, Keller JD (1990) Carbohydrate reserves, translocation and storage in woody plant roots. HortScience 25:274-281.

Lora J, Herrero M, Hormaza J (2009a) The coexistence of bicellular and tricellular pollen in Annona cherimola (Annonaceae): Implications for pollen evolution. Am J Bot 96:802-8. doi: 10.3732/ajb.0800167

Lora J, Testillano PS, Risueño MC, et al (2009b) Pollen development in Annona cherimola Mill. (Annonaceae). Implications for the evolution of aggregated pollen. BMC Plant Biol 9:129. doi: $10.1186 / 1471-2229-9-129$

Luza JG, Polito VS (1988) Microsporogenesis and anther differentiation in Juglans regia L.: A developmental basis for heterocichogamy in walnut. Bot Gaz 149:30-36.

Ma H (2005) Molecular genetic analyses of microsporogenesis and microgametogenesis in flowering plants. Annu Rev Plant Biol 56:393-434. doi: 10.1146/annurev.arplant.55.031903.141717

Mamun E A, Alfred S, Cantrill LC, et al (2006) Effects of chilling on male gametophyte development in rice. Cell Biol Int 30:583-91. doi: 10.1016/j.cellbi.2006.03.004

Mirgorodskaya OE, Koteyeva NK, Volchanskaya AV., Miroslavov E A. (2015) Pollen development in Rhododendron in relation to winter dormancy and bloom time. Protoplasma. doi: 10.1007/s00709015-0764-y

Ohnishi S, Miyoshi T, Shirai S (2010) Low temperature stress at different flower developmental stages affects pollen development, pollination, and pod set in soybean. Environ Exp Bot 69:56-62. doi: 10.1016/j.envexpbot.2010.02.007

Owen HA, Makaroff CA (1995) Ultrastructure of microsporogenesis and microgametogenesis in Arabidopsis thaliana (L.) Heynh . ecotype Wassilewskija (Brassicaceae). Protoplasma 185:7-21.

Pacini E (2010) Relationships between tapetum, loculus, and pollen during development. Int J Plant Sci 171:1-11. doi: doi.org/10.1086/647923

Pacini E, Bellani LM, Lozzi R (1986) Pollen, tapetum and anther development in two cultivars of sweet cherry (Prunus avium). Phytomorphology 36:197-210. 
Pacini E, Dolferus R (2016) The trials and tribulations of the plant male gametophyte - understanding reproductive stage stress tolerance. In: Shanker A, Shanker C (eds) Abiotic and Biotic Stress in Plants - Recent Advances and Future Perspectives. IntechOpen, pp 704-754

Pacini E, Jacquard C, Clément C (2011) Pollen vacuoles and their significance. Planta 234:217-27. doi: $10.1007 / \mathrm{s} 00425-011-1462-4$

Reale L, Sgromo C, Ederli L, et al (2009) Morphological and cytological development and starch accumulation in hermaphrodite and staminate flowers of olive (Olea europaea L.). Sex Plant Reprod 22:109-19. doi: 10.1007/s00497-009-0096-1

Richardson EA, Seeley SD, Walker DR (1974) A model for estimating the completion of rest for "Redhaven" and "Elberta" peach trees. HortScience 9:331-332.

Richardson EA, Seeley SD, Walker DR, et al (1975) Pheno-climatography of spring peach bud development. HortScience 10:236-237.

Rodrigo J, Herrero M (1998) Influence of intraovular reserves on ovule fate in apricot (Prunus armeniaca L.). Sex Plant Reprod 11:86-93. doi: 10.1007/s004970050124

Rodrigo J, Herrero M, Hormaza JI (2009) Pistil traits and flower fate in apricot (Prunus armeniaca). Ann Appl Biol 154:365-375. doi: 10.1111/j.1744-7348.2008.00305.x

Rodrigo J, Hormaza JI, Herrero M (2000) Ovary starch reserves and flower development in apricot (Prunus armeniaca). Physiol Plant 108:35-41. doi: 10.1034/j.1399-3054.2000.108001035.x

Rodrigo J, Rivas E, Herrero M (1997) Starch determination in plant tissues using a computerized image analysis system. Physiol Plant 99:105-110.

Rohde A, Bhalerao RP (2007) Plant dormancy in the perennial context. Trends Plant Sci 12:217-23. doi: 10.1016/j.tplants.2007.03.012

Ruiz R, García-Luis A, Monerry C, Guardiola JL (2001) Carbohydrate availability in relation to fruitlet abscission in Citrus. Ann Bot 87:805-812. doi: 10.1006/anbo.2001.1415

Saito T, Tuan P a., Katsumi-Horigane A, et al (2015) Development of flower buds in the Japanese pear (Pyrus pyrifolia) from late autumn to early spring. Tree Physiol 35:653-662. doi: 10.1093/treephys/tpv043

Smyth DR, Bowman JL, Meyerowitz EM (1990) Early flower development in Arabidopsis. Plant Cell 2:755-767. doi: $10.1105 /$ tpc.2.8.755

Thalmann M, Santelia D (2017) Starch as a determinant of plant fitness under abiotic stress. New Phytol 214:943-951. doi: 10.1111/nph.14491

Vogler H, Grossniklaus U, Hedhly A (2017) An introduction to male germline development. In: Schmidt A (ed) Plant germline development: methods and protocols. Humana Press Inc., Totowa, USA, pp 315. doi: 10.1007/978-1-4939-7286-9

Williams JH (2012a) Pollen tube growth rates and the diversification of flowering plant reproductive cycles. Int J Plant Sci 173:649-661. doi: 10.1086/665822

Williams JH (2012b) The evolution of pollen germination timing in flowering plants: Austrobaileya scandens (Austrobaileyaceae). AoB Plants 12:1-12. doi: 10.1093/aobpla/pls010

Zeeman SC, Kossmann J, Smith AM (2010) Starch: its metabolism, evolution, and biotechnological modification in plants. Annu Rev Plant Biol 61:209-34. doi: 10.1146/annurev-arplant-042809112301

Zini LM, Galati BG, Zarlavsky G, Ferrucci MS (2017) Developmental and ultrastructural characters of the pollen grains and tapetum in species of Nymphaea subgenus Hydrocallis. Protoplasma 1-14. doi: 
10.1007/s00709-016-1074-8 


\section{FIGURE CAPTIONS}

Fig. 1 Temperatures and chilling accumulation. Daily mean, maximum and minimum temperatures (black line surrounded by a grey area) and the Chilling Unit accumulation (thick black line). a Year 2010 - 2011. b Year $2011-2012$.

Fig. 2 Starch quantification in sweet cherry anther primordium. a Scheme of the anther primordium, showing the microsporangia ( $m s)$, the vascular bundle $(v b)$ and the connective tissue $(c t)$ where starch content was measured. b Image of an $\mathrm{I}_{2} \mathrm{KI}$-stained sample for starch. c Pseudocolor image corresponding to starch on the black and white image.

Fig. 3 Anther locules in sweet cherry along the seasons. a Flower primordia during dormancy, showing incipient verticiles: sepals (se), petals (pe), anthers (an) and pistil (pi). b Anther locule during the autumn, prior dormancy establishment, showing the sporogenous tissue (st) and the parietal cell layers ( $p c l)$. c Anther locule during dormancy, showing the pollen mother cells $(p m c)$, the tapetum $(t p)$ and the middle layers $(\mathrm{ml})$. d Anther locule at dormancy overcame, before meiosis, showing vacuoles (arrow). Scale bars $\mathbf{a}=500 \mu \mathrm{m}$, and $\mathbf{b}-\mathbf{d}=10 \mu \mathrm{m}$

Fig. 4 Duration of pollen development phases in days (grey bars) in sweet cherry from chilling fulfilment (snow flake) to flowering and accumulation of heat temperatures (Growing degree hours, GDH) (soft red)

Fig. 5 Microsporogenesis in sweet cherry. a Flower primordia during meiosis, when the flower bud is closed and covered by dark brown scales. b Pollen mother cell during "Prophase I"surrounded by callose (ca). c Coenocitic tetrads during "Telophase II", with four haploid nucleus surrounded by callose (ca). d Microspores in the tetrad separated by callose $(c a)$. Scale bars $\mathbf{a}=200 \mu \mathrm{m}$, and $\mathbf{b}-\mathbf{d}=10 \mu \mathrm{m}$

Fig. 6 Microgametogenesis in sweet cherry. a Flower appearance at microspore release at budburst. b Mononucleated microspores. c Vacuolated microspores, a polar view of two tricolpored grains; tapetum (tp) degeneration. d Flower appearance at balloon stage. e Young pollen grain binucleated, vegetative nucleus $(v n)$ and generative nucleus $(g n)$ stained with DAPI, with the exineand intine . f Young pollen grain showing starch (arrow) accumulation; tapetum disappearance and middle layer ( $\mathrm{ml}$ ) with fibrous 
thickening. g Flower appearance at anthesis. h Mature pollen grain showing the colpi (arrow). i Mature pollen grain; middle layer $(\mathrm{ml})$ collapsed. Scale bars $\mathbf{a}, \mathbf{d}, \mathbf{g}=2 \mathrm{~mm}$, and $\mathbf{b}, \mathbf{c}, \mathbf{e}, \mathbf{f}, \mathbf{h}, \mathbf{i}=10 \mu \mathrm{m}$

Fig. 7 Starch content in anther connective tissue, anther diameter, accumulation of chilling temperatures (in blue) until chilling fulfilment (snow flake), and accumulation of heat temperatures (Growing degree hours, GDH) from chilling fulfilment until flowering in two sweet cherry cultivars over two years. a "Bing", cold year. b "Bing", mild year. c "Burlat", cold year. d "Burlat", mild year. r, Pearson's correlation coefficients between the anther size and heat accumulation from chilling fulfilment until tetrads formation. $* \mathrm{P}<0.05 ; * * \mathrm{P}<0.01$. Different letters (a-e) indicate significant differences $(\mathrm{P}<0.05)$.

Fig. 8 Anther vascular differentiation in sweet cherry. a Undifferentiated prevascular area during dormancy. b Connective tissue before meiosis, showing starch accumulation. c First tracheary elements (arrows) just before microspore meiosis. d Connective tissue after microspore meiosis with starch traces. e Developed vascular tissue showing numerous xylem vessels (transverse section). Scale bars $=20 \mu \mathrm{m}$ 


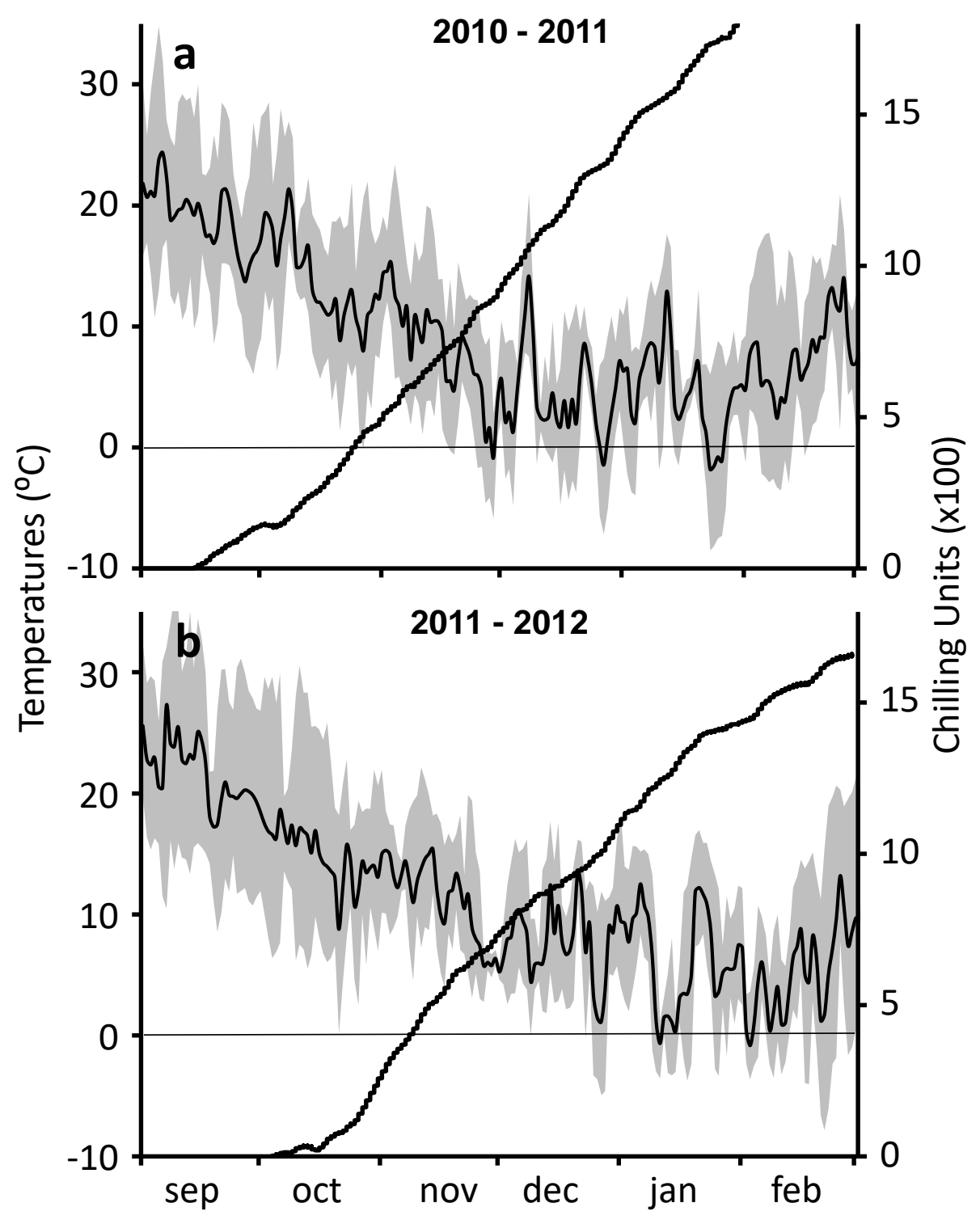


$b=+4,2, c^{2}+c^{2}$
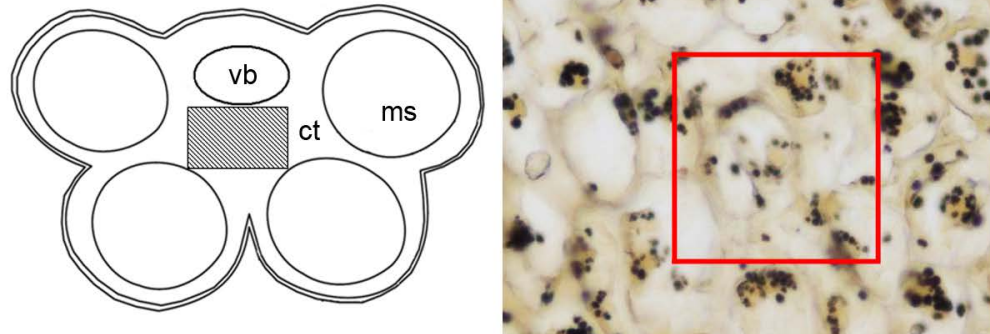
at is $4 \%$ M.

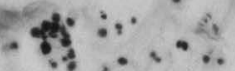




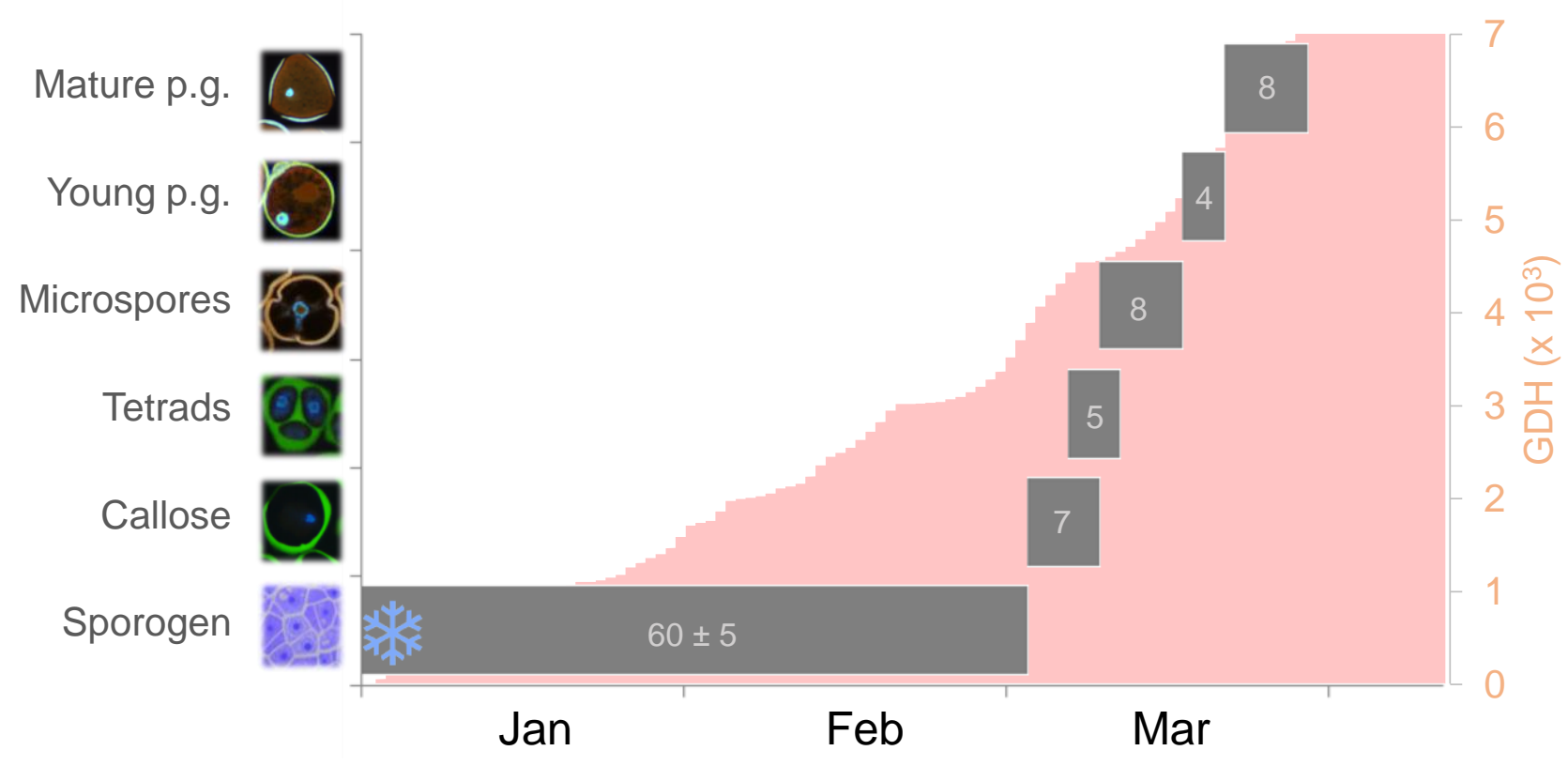




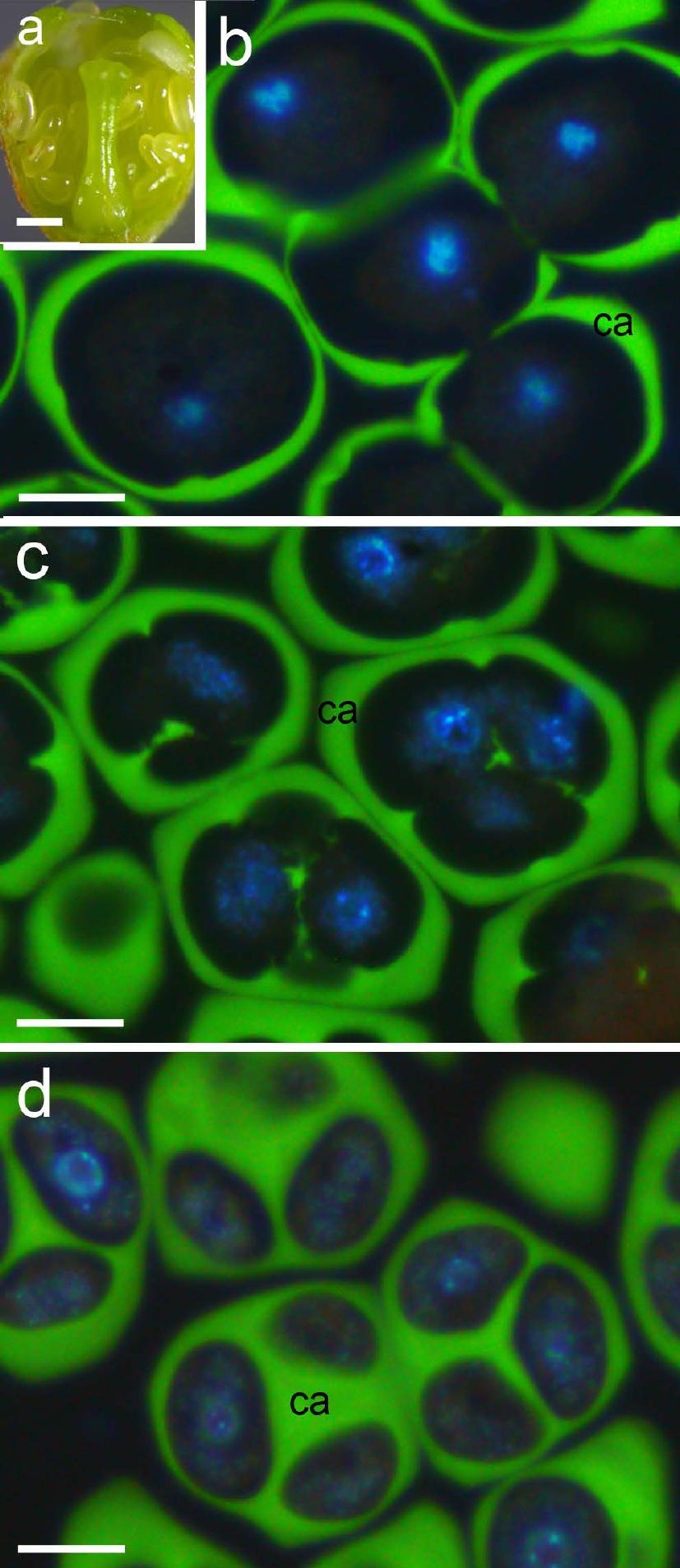




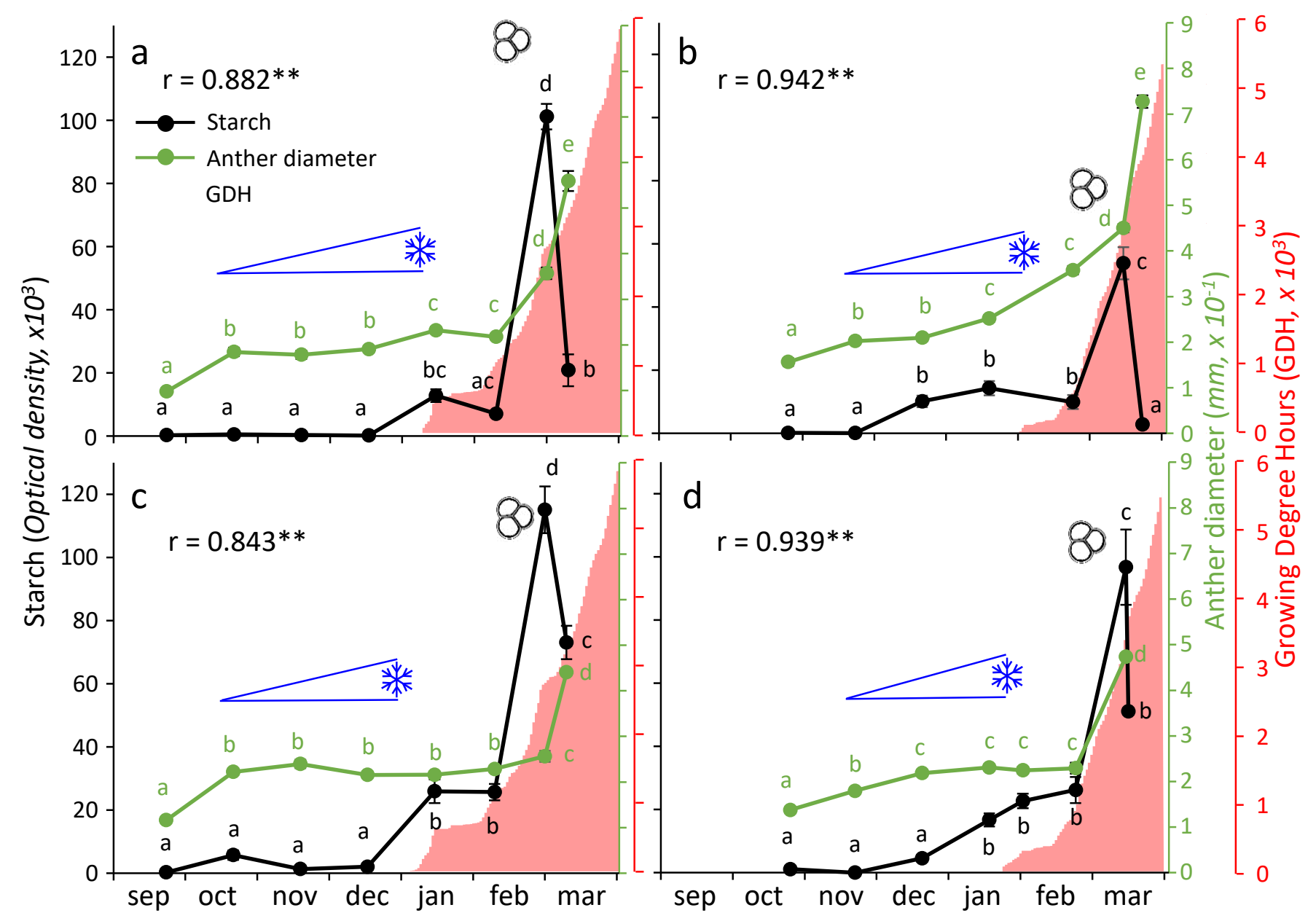




\section{a}

$60.0^{\circ}$
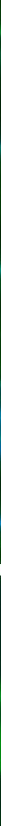

C
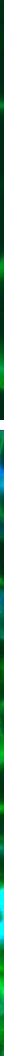
Table 1: Stages of flower bud development of sweet cherry according to the BBCH scale (Fadón et al. 2015).

Principal growth BBCH stage 5: reproductive development or inflorescence emergence

50 Dormancy: inflorescence buds closed and covered by dark brown scales

51 Inflorescence bud swelling: buds closed, light brown scales visible

53 Bud burst: scales separated, light green bud sections visible

54 Inflorescence enclosed by light green scales

55 Single flower buds visible

56 Flower pedicel elongating: sepals closed; single flowers separating

57 Sepals open: flowers with white petals (still closed)

59 Balloon stage: sepals completely opened, petals completely extended and rounded but still closed 